\title{
INFANTILISM WITH BONY CHANGES RESEMBLING RICKETS AND CALCI- FICATION IN KIDNEYS
}

BY

\author{
CÉCILE ASHER, M.D., B.Sc., D.C.H., \\ (From the Alder Hey Hospital, Liverpool.)
}

The following case is reported because it shows unusual features:-

R. R. first came under observation on January 12, 1934, at the age of two years, when he was admitted to Alder Hey Hospital with the complaint that he was unable to walk. He was the fifth child of healthy parents. One child had died of measles; the others were reported to be well. The patient's birth had been normal, with an easy confinement and

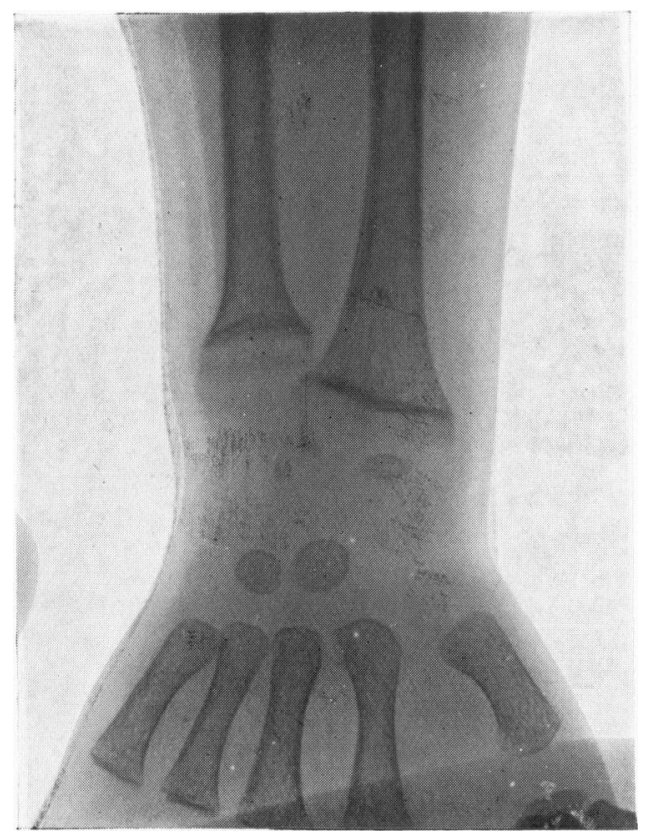

Fig. 1.-R. R., 1.2.34. Skiagram of wrist.

the birth weight was eight pounds. Up to the age of ten months he appeared to be developing normally, but from this time onwards he ceased to grow. He began to walk at the age of twelve months, but three months later he ' went off his feet,' and crawled about the floor until his first admission. His teeth appeared early, but his mother could not remember the exact dates of dentition. He was fed on dried milk until eleven months old and 
then on condensed milk for a month. After this he was given a mixed diet. Three teaspoonsful of cod-liver oil emulsion were given daily from the age of eleven months to the age of seventeen months.

ON EXamination he was found to be small and under-nourished, weighing only $17 \mathrm{lb}$. His height was $2 \mathrm{ft} .8 \mathrm{in}$. His anterior fontanelle was. closed and primary dentition was complete. There was no deformity of the

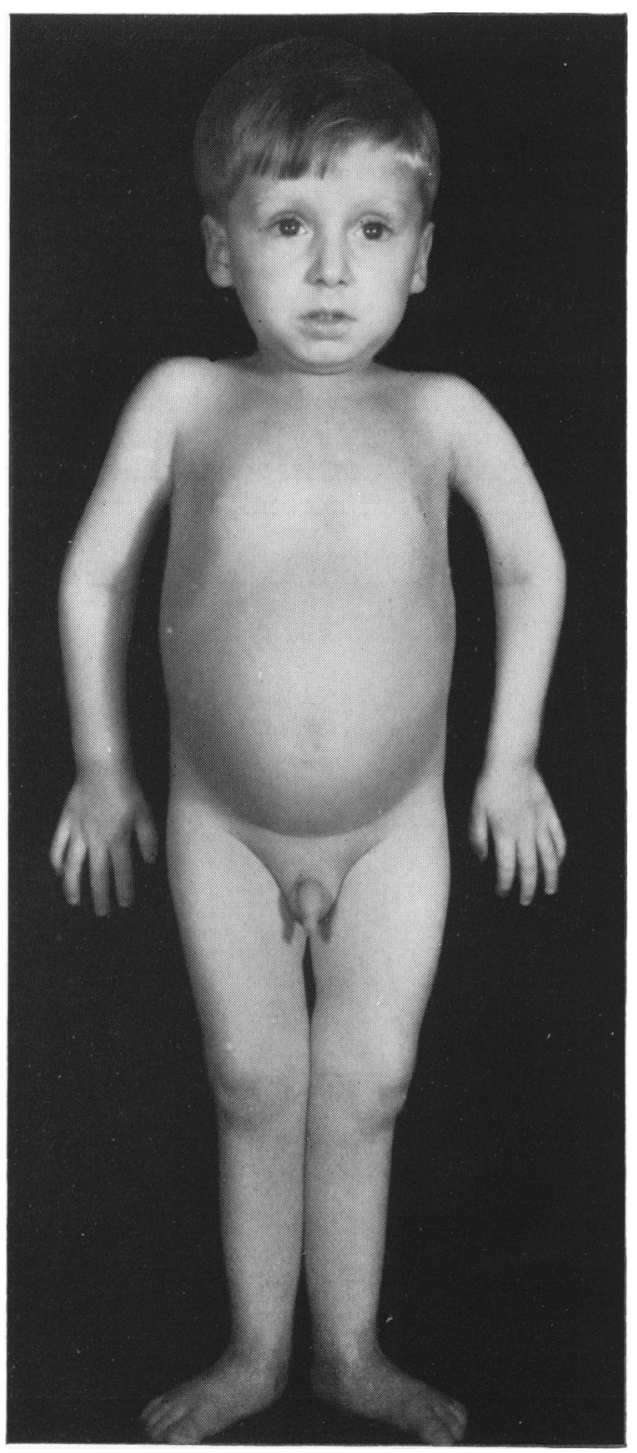

FIg. 2.-R. R., age 3 years, 4 months.

chest, but a slight degree of genu valgum was present. The epiphyses were enlarged and radiological examination of his wrists showed the presence of active rickets (fig. 1). He was treated with cod-liver oil (3,000 international units of vitamin $\mathbf{D}$ daily), and ultra-violet light (one minute increasing to twenty minutes at a distance of 22 inches) three times a week. Radio- 
logical examination of the radial epiphyses at the end of a month showed a very slight attempt at healing. He then developed an acute febrile attack, for which he was isolated. His parents removed him on their own responsibility on February $6,1934$.

He was re-admitted on May 25, 1935, again with the complaint of not being able to walk. On examination he was found to be still underweight, weighing only $18 \mathrm{lb} .8 \mathrm{oz}$. at the age of three years, four months (fig. 2). Radiological examination showed the presence of active rickets, and of a fractured left ulna. The child developed broncho-pneumonia four days after admission, from which he recovered entirely in three weeks. On June 15, 1935, he was found to have a fracture of the right humerus.

The fractures were treated by means of suitable splints, and 3,000 units vitamin $\mathbf{D}$ were given daily in the form of an oily solution of calciferol.

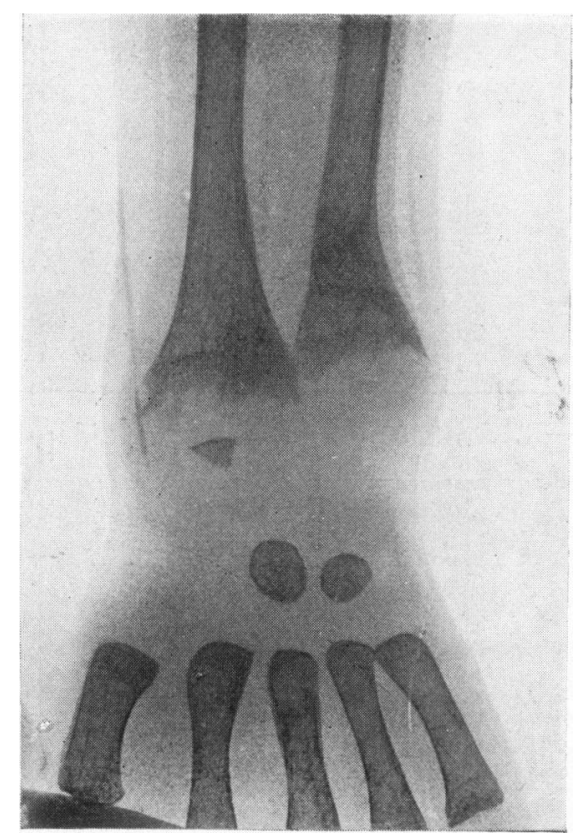

Fig. 3.-R. R., 8.7.35. Skiagram of wrist.

Ultra-violet light (one minute, increasing to twenty minutes, at a distance of 22 inches) was given three times a week. The treatment was continued for five months, but no radiological healing of the epiphyses occurred (fig. 3). The following investigations were then carried out:-

29.10.35. BLOOD UREA 20 mgm. per 100 c.c.

15.11.35. , ", $21 \quad, \quad, 100$ c.c.

8.11.35. BLOOD CALCIUM 7.27 ", ", 100 c.c. BLOOD PHOSPHORUS $6.25 \mathrm{mgm}$

17.11.35. " , 7.52 ", ", 100 c.c. , , 4.75 ,

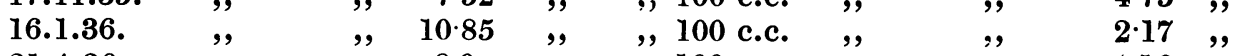

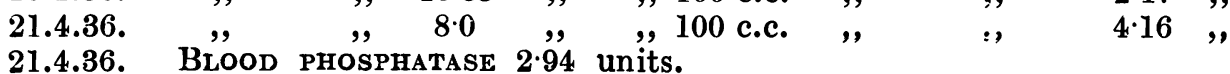




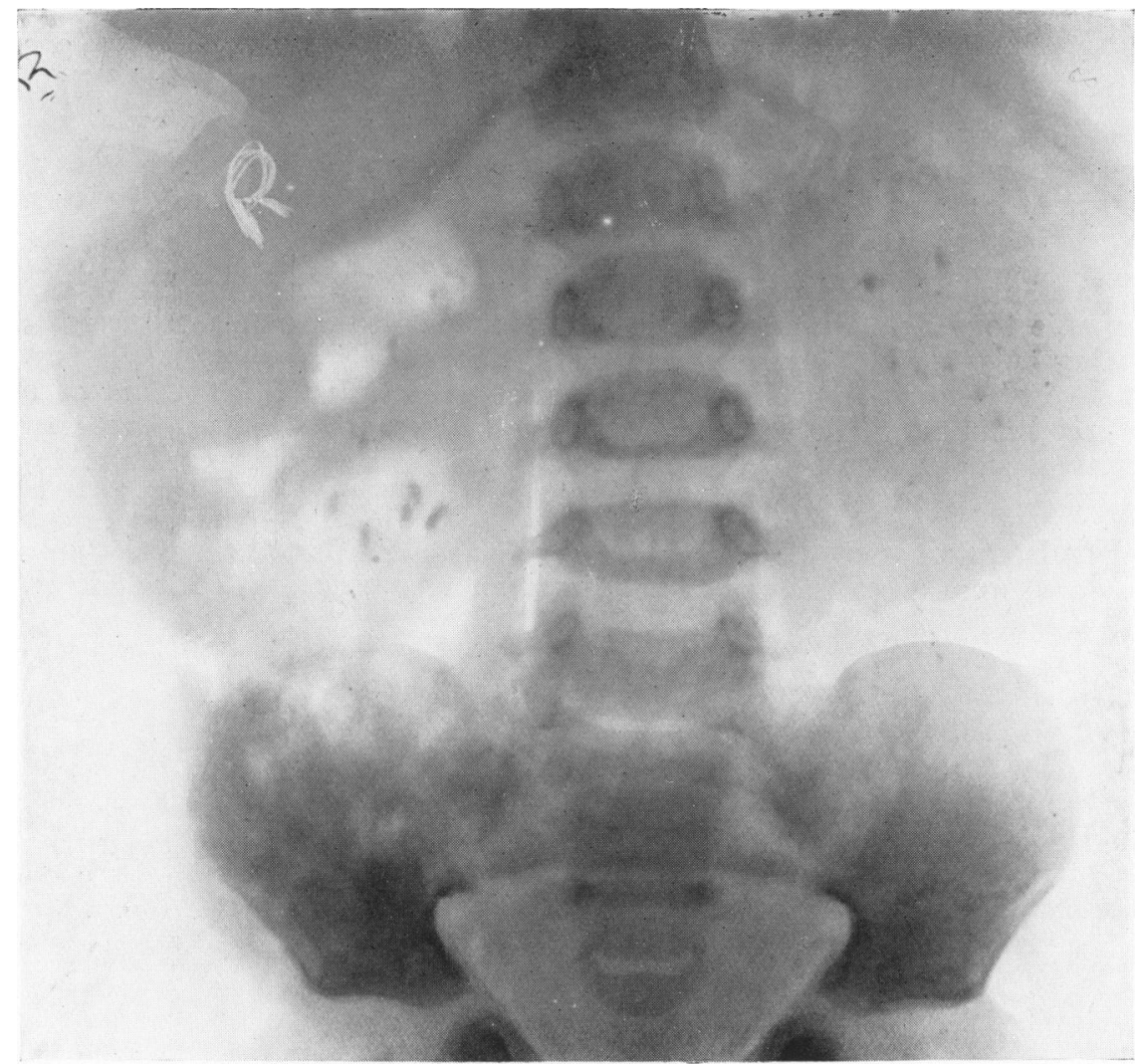

FIG. 4.-R. R., 22.11.35. Skiagram of kidneys.

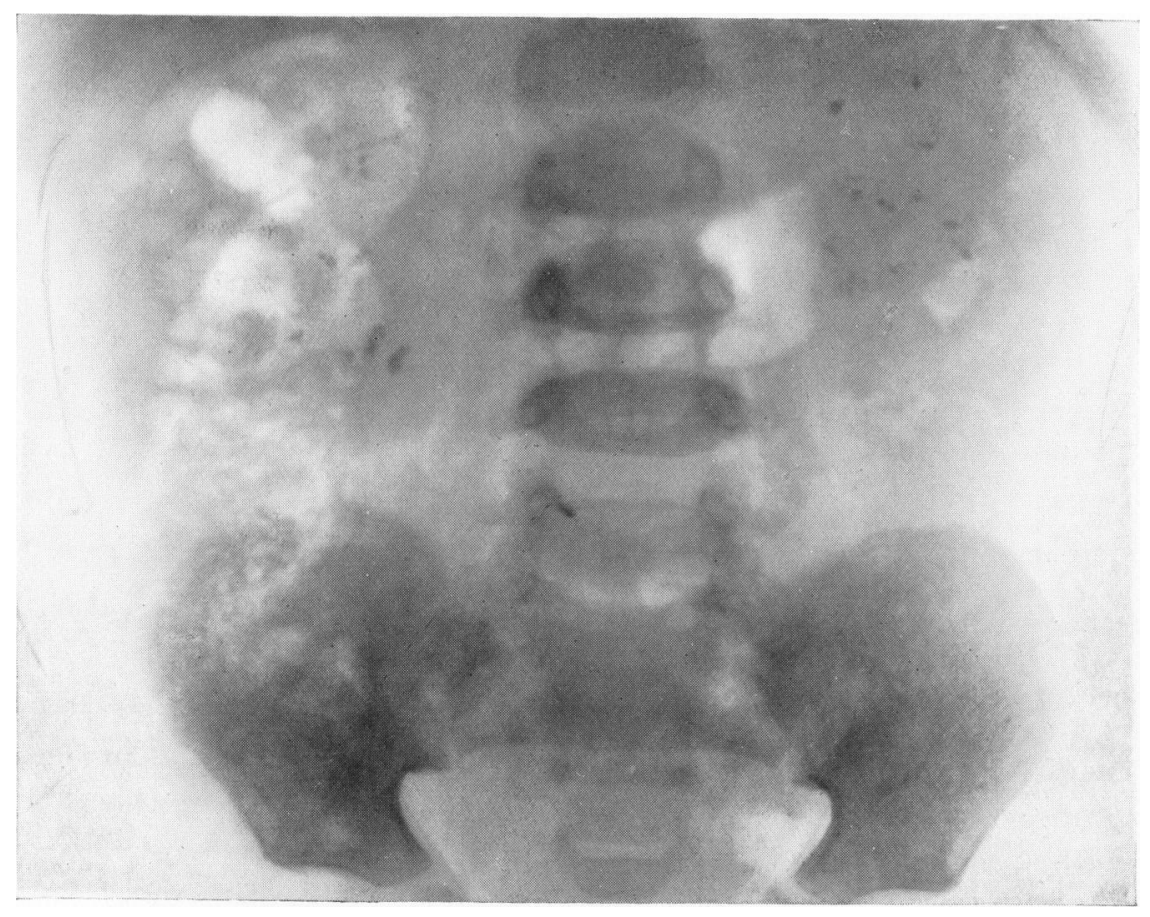

FIG. 5.-R. R., 21.4.36. Skiagram of kidneys. 
17.1.36. Calcium balance.

Total intake of $\mathrm{CaO}$ in twenty-four hours 1,124.4 mgm.

, output ," , , , , , $961 \cdot 6$,

12.11.35. Fat CONTENT OF FAECES.

$162 \cdot 8$,

Unsplit (neutral fat) ... $\quad 3 \cdot 88$

Split fat $\quad \ldots \quad \ldots \quad 17 \cdot 15$ per cent. of dried faeces.

Total fat $\quad \ldots \quad \ldots \quad 21 \cdot 0\}$

29.5.36. AlKali ReSERve $50 \cdot 2$ vol. $\mathrm{CO}_{2}$ per 100 c.c.

Urine eXaminations. Specific gravity averaged 1006.

Albumin and sugar were never found.

An occasional leucocyte was seen in the deposit.

Casts were not found on any occasion.

The Wassermann reaction of the blood was negative.

The Mantoux Reaction (1/1000) was negative.

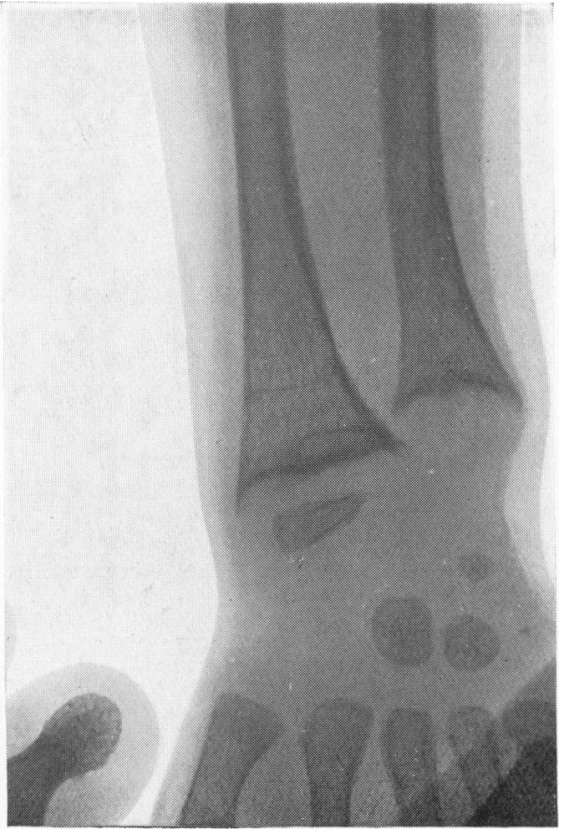

Fig. 6.-R. R., 6.4.36. Skiagram of wrist.

The BLOOD COUNT:-

No. of Red cells $2,300,000$ per c.mm. Differential count.

, White cells 7,000, ,, Small mononuclears 57 per cent.

Haemoglobin ... 40 per cent. Large,,$\quad 5$, ,

Polymorphonuclears $35,$, ,

Eosinophils $\quad 2 \cdot 7$, ,

Mast cells ... $\quad$-3 ,, ,

22.11.35. Radiological EXamination (fig. 4 and 5) of renal tract showed small areas of calcification scattered throughout the kidney substance.

Progress. The general condition of the child improved; he looked better, grew more cheerful and gained weight. Anti-rachitic treatment (ultra-violet light and added vitamin D) was discontinued when the renal calcification was discovered, but he was allowed a liberal diet. Daily 
massage and exercises were given, and as a result of this treatment he learned to walk and was soon able to progress unassisted around the ward. His klood picture became normal after administration of iron by mouth, but serial radiographs of his radial epiphyses showed little, if any, improvement, and on May 15, 1936, he fell and re-fractured his right humerus (fig. 6 and 7).

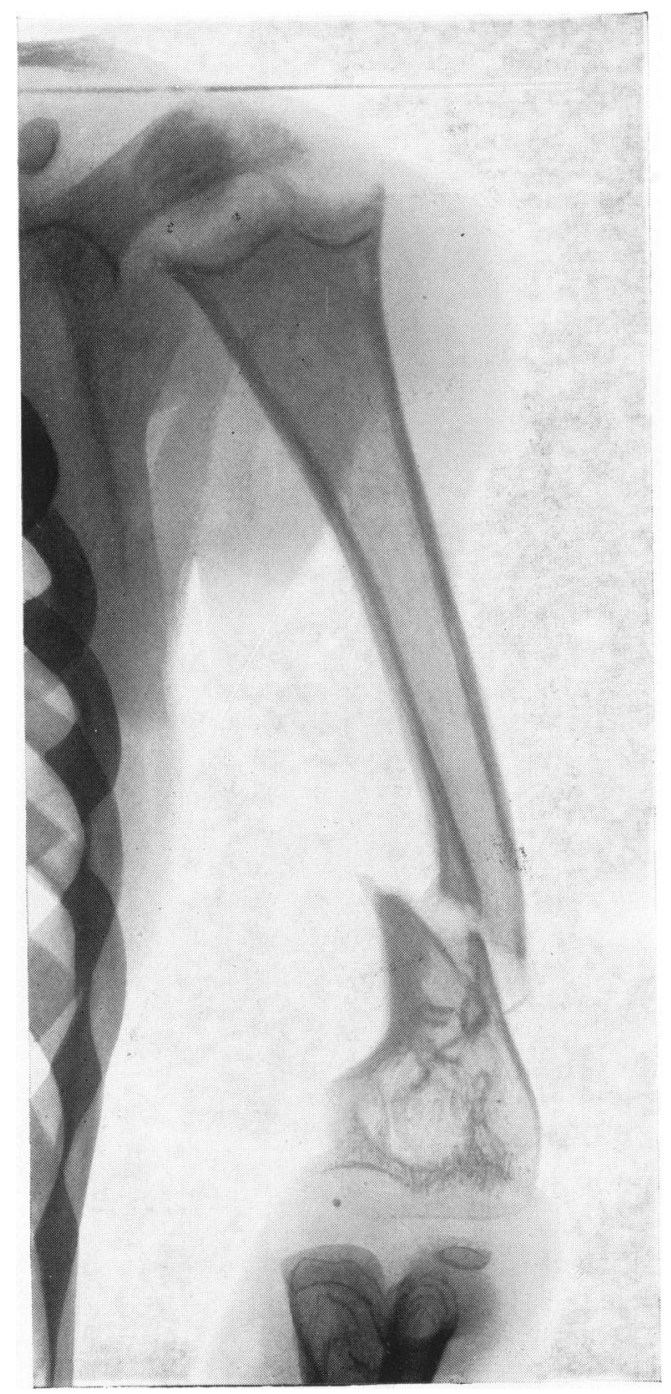

FIG. 7.-R. R. 15.5.36. 'Skiagram of humerus.

Discussion.

It is difficult to determine the nature of the underlying disturbance which has been responsible for the infantilism, the renal calcification, and for the presence of ' rickets,' which has failed to respond to treatment with adequate doses of vitamin $\mathbf{D}$ and ultra-violet light. 
The following conditions have to be considered as possible causes :-

(1) Lack of vitamin D and sunlight. That the rickets cannot be due solely to vitamin $\mathbf{D}$ deficiency is shown by the fact that after five months' treatment no healing took place. The renal calcification suggests that while absorption of calcium from the intestine was adequate, normal redistribution and utilisation in the body did not take place; thus calcium would be deposited in the kidneys during concentration of urine containing excess of calcium salts.

(2) 'Renal rickets.' The fact that the bone changes are associated with infantilism suggests this as a possible diagnosis, but the biochemical findings do not support it. The renal function is normal and the blood phosphorus has never reached a high figure.

(3) Coeliac disease. This, too, would account for the presence of infantilism and bony changes resembling rickets. The child, however, does not present the clinical features associated with coeliac disease, nor does the analysis of the stools bear out such a diagnosis.

(4) Acidosis. Lightwood ${ }^{1}$ recently reported a case of renal calcification associated with acidosis. There is no evidence that this is a causal factor here. The alkali reserve estimated by van Slyke's method, is normal.

(5) Parathyroid hyperplasia. It is possible that hyperplastic changes have occurred in the parathyroids, which prevent the healing of the rickets. The blood calcium, however, has never reached a high level.

No single factor seems to offer an adequate explanation of the condition. It is possible that a deficiency of vitamin $D$ and a hyperplasia of the parathyroids are both concerned. Experimental work has shown that the parathyroids hypertrophy when the diet is deficient in calcium. Luce ${ }^{2}$ found that rats fed on a diet deficient in calcium, show a consistent enlargement of the parathyroid gland, and concludes that the parathyroids are making an attempt by an increase in normal functioning cells to supply a metabolic need, arising from calcium deprivation. She says: 'The nature of this need is not proven, but it may be that in the absence of calcium the organism is unable to make full use of the growth factor in diet.' Erdheim ${ }^{3}$ has described an enlargement of the parathyroid gland in spontaneous rickets in rats, and Pappenheimer ${ }^{4}$ has described enlargement of the gland with hyperplasia of cells in human rickets. Ritter ${ }^{5}$ also has reported increased connective tissue, hyperaemia and oedema in the parathyroids of rachitic children. Langmead and $\mathrm{Orr}^{6}$ have described changes in the parathyroids secondary to renal rickets.

\section{Conclusion.}

The case does not present an uncomplicated clinical picture. Any explanation must be in the nature of a hypothesis. It may be, that, the rickets having remained untreated for a year, the child was in a state of calcium deprivation owing to failure of absorption, and hence parathyroid hyperplasia occurred. When calcium was restored to the child by the administration of vitamin $\mathbf{D}$ and ultra-violet light, in addition to a good 
diet, the over-activity of the parathyroids prevented calcium from being laid down in the bone and caused its deposition in the kidneys during concentration of the urine.

\section{Summary.}

A case of infantilism with renal calcification and bony changes resembling rickets, which failed to heal completely under anti-rachitic treatment, is described. The biochemical investigations are recorded. It is shown that the case cannot be explained by vitamin $\mathbf{D}$ deficiency, disordered renal function, coelic disease, acidosis or parathyroid hyperplasia alone. Parathyroid hyperplasia secondary to unhealed rickets, persisting after the exhibition of vitamin $\mathrm{D}$, is suggested as a possible cause.

\section{REFERENCES.}

1. Lightwood, R., Lancet, London, 1936, i, 1239.

2. Luce, E. M., J. Path. \& Bact., Edinburgh, 1923, XXVI, 200.

3. Erdheim, Rachitis und Epitheilkorperden, Vienna, 1914.

4. Pappenheimer, A. M., \& Minor, J., J. Exper. Med., New York, 1921, XLIII, 391.

5. Ritter, C., Frankfürt Ztschr. f. Path., Munich, 1920, XXIV, 137.

6. Langmead, F. S., \& Orr, J. W., Arch. Dis. Childh., London, 1933, VIII, 265. 